\title{
Investigation on the characterization and properties of EH36 steel FCB welded joint
}

\author{
Kai Wang ${ }^{1, a}$, Zexin Jiang ${ }^{2, b}$, Jinjun $\mathrm{Ma}^{2, \mathrm{c}}$, Chen $\mathrm{Rui}^{3, \mathrm{~d}}$, \\ Ben $\mathrm{Niu}^{3, \mathrm{e}}$, Yaoyong $\mathrm{Yi}^{3, \mathrm{f}}$ \\ ${ }^{1}$ Foshan University, Foshan, Guangdong, 528000, China \\ ${ }^{2}$ Guangzhou Shipyard International Co., Ltd, Guangzhou, 511462, China \\ ${ }^{3}$ Guangdong Welding Institute (CUPIW), Guangzhou, 510610, China \\ awk927@qq.com, ${ }^{\text {b}} 13533186287 @ 163 . c o m,{ }^{c}$ meiyuxiao2004@aliyun.com, d461501074@qq.com, \\ eniu1402898779@163.com, 'yiyy@gwi.gd.cn
}

Keywords: EH36, High strength steel, FCB, Microstructure, Electrochemical behavior

Abstract. The characterization and properties of TMCP EH36 high strength steel fabricated by the flux copper backing (FCB) one-side SAW process with a high weld heat input of $190 \mathrm{KJ} / \mathrm{cm}$ were studied. The mechanical properties of the FCB welded joint was tested. The structural characteristics and microstructural features of the FCB welded joint were analyzed using optical microscope $(\mathrm{OM})$. The microhardness distributions along the cross section of the FCB welded joint were studied to figure out the details of the weld softening phenomena. The electrochemical tests were carried out in the three-electrode system to analyze the electrochemical behavior of the welded metals (WM). The symmetrical heat affected zone (HAZ) structure and uniform WM microstructure of tiny acicular ferrites were revealed.

\section{Introduction}

The thermal mechanical control process (TMCP) combining the controlled rolling with on-line accelerated cooling is now widely used to produce the high strength steel plates [1]. The steel plates are immediately cooled by the water rapidly through a temperature range from $800^{\circ} \mathrm{C}$ to $500^{\circ} \mathrm{C}$ after the previous hot rolling, then air-cooled to the room temperature. The microstructures of the TMCP steels are highly refined to significantly improve the strength and toughness of the steels [2]. Nowadays, the TMCP EH36 steel is widely used in the off-shore engineering applications, the ship building industry and the pipeline steel for transporting gas and oil.

Those off-shore engineering structures, ships and pipelines have high requirements to the mechanical quality of the weld joints. In general, the researchers and technicians paid abundant attention to the mechanical properties of the weld joints of the TMCP EH36 steel. It is found that the welding joints are the weak points, and developed the special welding materials and method for the high-efficiency welding of the TMCP EH36 steel [3]. The phenomena of the corrosion of the weld joints in the ships are unavoidable and severe. Corrosion is always an important and unavoidable problem in the ship building industry. All those ships and off-shore engineering equipment are difficult to be maintained and serve in easily-corrosive severe environments for abundant problems caused by corrosion. However, seldom research focused on the comprehensive properties of mechanical and electrochemical properties of the EH36 weld joints, even the weld joints serve for an extremely long time under the seawater. By determining the welding consumables and base metals, the comprehensive properties of the weld joints are mainly affected by the welding technology. The variation of the comprehensive properties is caused by the lax control of the welding parameters, which are necessary to control in proper range [4]. For the welding conditions, the weld heat input is the aggregative indicator to response the welding current, voltages and speeds, as is one of the most important factors to determine the combination properties of the welding joints.

As one of the high weld heat input welding technologies, the FCB-SAW is well known as a 
high-efficiency welding method widely used in the ship building industry, which usually use 3 electrodes to realize the single face welding with double face forming, as greatly improve the welding efficiency by high weld heat input, whose weld heat input can reach over $150 \mathrm{~kJ} / \mathrm{cm}$. In general, such high weld heat input is easy to result in grain coarsening, to promote the generation and growth of such undesirable structures as the grain boundary ferrites (GBF), ferrite side-plates (FSP), bainites and martensite-austenite (M-A) constituents. It is studied by Zhao et al. that those undesirable structures would result in a deterioration of the mechanical properties of the WM [5]. However the electrochemical behavior of the FCB WM has not been reported yet. It is necessary to study the influence of the microstructural characterizations on the comprehensive properties of the TMCP EH36 high strength steel weld joints by high weld heat input FCB method. In this paper, the TMCP EH36 steel FCB weld joint was fabricated at a weld heat input of $190 \mathrm{~kJ} / \mathrm{cm}$ to analyze the on the characterization and properties of the FCB welded EH36 steel.

\section{Experimental}

The material employed in this work was a TMCP EH36 steel with a thickness of $32 \mathrm{~mm}$. The chemical composition of the steel in weight percent was $0.07 \mathrm{C}, 1.47 \mathrm{Mn}, 0.15 \mathrm{Si}, 0.13 \mathrm{Ni}, 0.07 \mathrm{Cr}$, $0.005 \mathrm{P}, 0.002 \mathrm{~S}$, with rare $\mathrm{Nb}, \mathrm{Cu}, \mathrm{Ti}$ and $\mathrm{N}$, and Fe balanced. The $\mathrm{CE}$ was calculated to be 0.35 according to the equation, $\mathrm{CE}=\mathrm{C}+\mathrm{Mn} / 6+\mathrm{Cr}+\mathrm{Mo}+\mathrm{V} / 5+\mathrm{Cu}+\mathrm{Ni} / 15$ [9]. The steel with the yield of strength $515 \mathrm{MPa}$ is usually used for the construction of ship structures, the details are shown in Table 1. Table 2 shows the chemical composition of the TMCP EH36 steel. The size of the steel plate is $300 \mathrm{~mm} \times 150 \mathrm{~mm} \times 32 \mathrm{~mm}$, assembled with the $\mathrm{V}$ groove of $50^{\circ}$ to weld by FCB-SAW. The FCB welding was carried out by using two types of Y-DL flux-cored wires, setting the same flux-cored wire as the leading and middle wire of $4.8 \mathrm{~mm}$ diameter, and the other type of flux-cored wire as the back wire of $6.4 \mathrm{~mm}$ diameter. Choose the NSH-55ER flux as the FCB surface flux of and the NSH-1RM flux as the pad flux. The welding parameters are as follow: the voltage and the current of the front wire is $1340 \mathrm{~V}$ and $35 \mathrm{~A}$; the voltage and the current of the middle wire is $1170 \mathrm{~V}$ and 41A; the voltage and the current of the back wire is $1280 \mathrm{~V}$ and $47 \mathrm{~A}$; the welding speed is $50 \mathrm{~cm} / \mathrm{min}$. The FCB weld heat input is calculated as $190 \mathrm{~kJ} / \mathrm{cm}$. The weld joint was cooled in the air at room temperature after welding. Before the electrochemical tests, the samples were polished by 2000 grid sand paper, degreased by acetone, washed by the distilled water and dried by the blower.

The microhardness of the joints were tested by a DHV-1000Z micro Vickers hardness tester according to the marks of line $\mathrm{a}$ and $\mathrm{b}$ in Fig. 1, with $200 \mathrm{~g}$ load and $20 \mathrm{~s}$ loading time, starting from $15 \mathrm{~mm}$ on the left side of the welding joint to acquire a vikers hardness value every $1 \mathrm{~mm}$, each line-a and line-b site for 60 points along the horizontal direction of the joints. The Linear Polarization (LP) and Electrochemical Impedance Spectroscopy (EIS) test samples were prepared from the center of the weld metal along the longitudinal direction by linear cutting, with the size of $90 \mathrm{~mm} \times 10 \mathrm{~mm} \times 0.5 \mathrm{~mm}$, marked as the block 1 block 3 in Fig. 1, respectively. Each sample was observed and analyzed by OM, respectively. Before the LP and EIS tests, the samples were polished by 2000 grid sand paper, degreased by acetone, washed by the distilled water and dried by the blower. The working areas of the tested samples were prepared as $1 \mathrm{~cm}^{2}$, the other parts of the samples were sealed by wax. The LP and EIS testes were carried out by an Autolab PGSTAT302N electrochemical workstation in the three-electrode system: the working electrode was the tested sample $\left(1 \mathrm{~cm}^{2}\right.$ working area), the auxiliary electrode was the Pt plate, the reference electrode was $\mathrm{Ag} / \mathrm{AgCl}(3 \mathrm{~mol} / \mathrm{L} \mathrm{KCl})$, the electrolyte was $3.5 \mathrm{wt} \% \mathrm{NaCl}$ water solution. Before testing the working electrode was soaked in the electrolyte by the open circuit potential (OCP) mode for 30 min. The LP mode was set as the scanning potential range of $\pm 15 \mathrm{mV}$ vs OCP and scanning speed of $1 \mathrm{mV} / \mathrm{s}$. The EIS mode was set as OCP, with the frequency of 104 10-2 Hz, and the AC drive signal amplitude is set to $\pm 5 \mathrm{mV}$. 


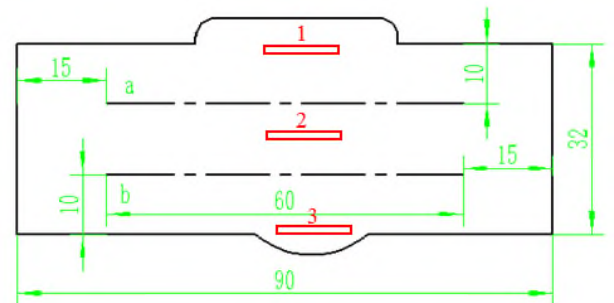

Fig. 1 Sketch maps of microhardness and electrochemical testing sampling.

Table 1. Mechanical properties of TMCP EH36 steel.

\begin{tabular}{cccccccc}
\hline Yield Strength & Tensile Strength & Elongation rate & Impact & Gap & Site & SPEC & Energy \\
\hline $515 \mathrm{MPa}$ & $580 \mathrm{MPa}$ & $22 \%$ & $-40^{\circ} \mathrm{C}$ & $\mathrm{V}$ & $1 / 4$ & $\mathrm{~A}$ & 170 \\
\hline
\end{tabular}

Table 2. The experimental chemical composition of TMCP EH36 steel (wt.\%).

\begin{tabular}{ccccccccc}
\hline $\mathrm{C}$ & $\mathrm{Si}$ & $\mathrm{Mn}$ & $\mathrm{P}$ & $\mathrm{S}$ & $\mathrm{V}$ & $\mathrm{Ni}$ & $\mathrm{N}$ & $\mathrm{Cr}$ \\
\hline 0.07 & 0.15 & 1.47 & 0.005 & 0.002 & 0.003 & 0.13 & 0.0041 & 0.07 \\
\hline
\end{tabular}

\section{Results and Discussion}

Microstructure Analysis. The typical structure of the FCB weld joint is consisted of WM, HAZ and base metal (BM). The HAZ with different distances from the fusion line would be transformed into various microstructures at different peak temperatures (PT) and cooling rates [6, 7]. In this paper, the HAZ of FCB welded EH36 steel is categorized into four distinct regions according to different PT: (1) the coarse-grained HAZ (CGHAZ), (2) the transition zone, (3) the fine-grained HAZ (FGHAZ), and (4) the inter critical HAZ (ICHAZ), seen Fig. 2. Due to the effect of the high weld heat input and the chemical composition and characterization of the TMCP EH36 steel, a transition zone formed between the CGHAZ and the FGHAZ though the peak temperature in this special zone is over the temperature of complete austenitization (Ac3). It can also be observed from Fig. 2 that the FCB weld joint shows mirror symmetry centered to the WM center. The geometric shape and area of each distinct HAZ region on both side of the WM center is near the same.

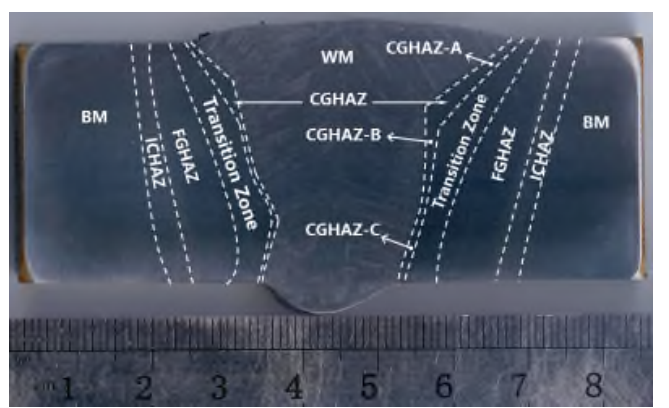

Fig. 2 The structure of the FCB welded joint.

The CGHAZ is the weakest zone in the weld joint, for its lowest toughness because of grain coarsening and high hardness [8-10]. The thickness of CGHAZ at different position was calculated, respectively (Fig. 3). The average thickness of the CGHAZ is about $1.0 \mathrm{~mm}$. The maximum thickness of CGHAZ-B reach $1.7 \mathrm{~mm}$, caused by the weld heat input concentration near the crossing position of the back wire and the middle wire. The minimum thickness of CGHAZ-C is $0.5 \mathrm{~mm}$ related to the lowest weld heat input as close to the lead wire. The morphologies of each CGHAZ were observed by OM, Fig. 4. The CGHAZ are mainly consisted of intergranular acicular ferrites (IAF), grain boundary ferrites (GBF), and small amount of bainites. 

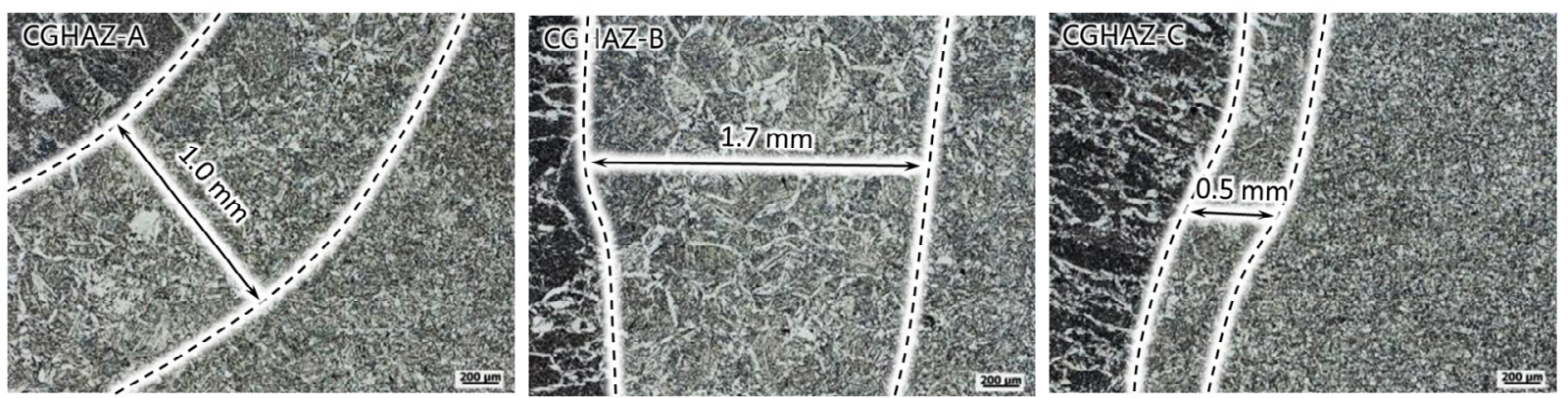

Fig. 3 Thickness of the CGHAZ at different position.
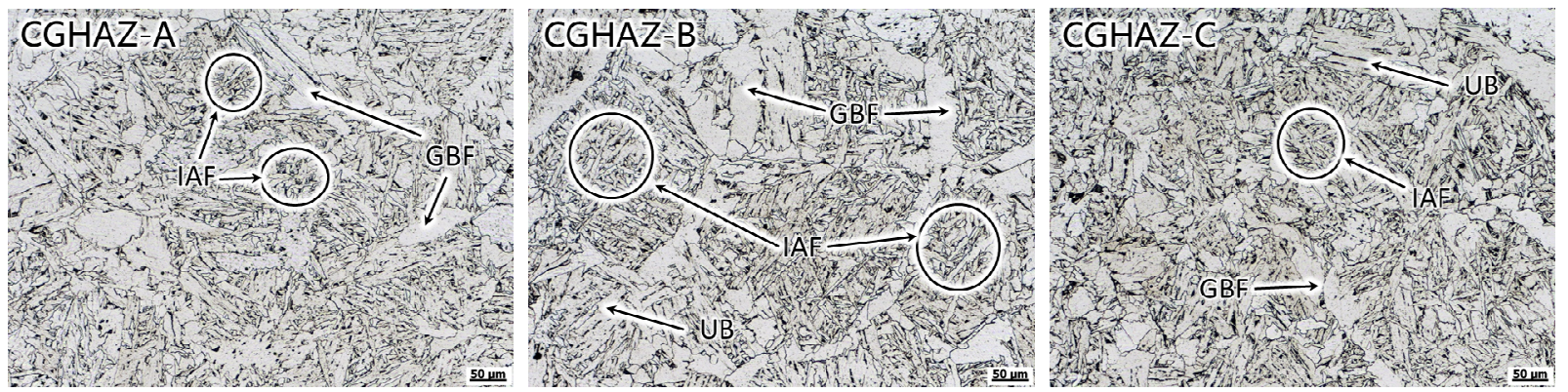

Fig. 4 Optical microstructure of the CGHAZ at different position.

Fig. 5 shows the microstructures of the FCB WM at different regions that are mainly consisted of AF, grain-boundary ferrite (GF), and dispersively distributed martensite-austenite constituent (M-A) or nonmetallic inclusions. From the top WM1 to the root WM3 along the longitudinal direction, the particle sizes of the GF gradually become smaller in a narrow range. For the high weld heat input of the FCB technology and the single-pass welding form, the melten WM has a high cooling rate and supercooling ratio. It resulted in the shrink of the primary ausinite and the second phase particles, as the martensite-austenite constituent (M-A) or the nonmetallic inclusions [11, 12], seen in Fig. 3. The M-A il ands or the inclusions in the FCB WM, which could further reduce the nucleations and the interface's free energy. Those composite factors are favorable for the nucleation and formation of the acicular ferrite and to inhibit the growth of the GF structure [13]. Besides, the high cooling rate would decrease the austenitic isothermal time during FCB weld, which is unfavorable for the long-range diffusion of carbon atom. The quantity of the carbon concentrated in the primary austenite would be accelerated by the high cooling rate caused by the high weld heat input, which favor the nucleation of the ferrite organization. When the carbon concentration reaches a critical value, then the formation of the ferrite is prevented by the stabilization of the primary austenite, resulted in the growth of AF structure. By the function of the low-carbon and low-alloy WM in a high cooling rate, the growth of AF could be full enough resulted by the high FCB weld heat input.
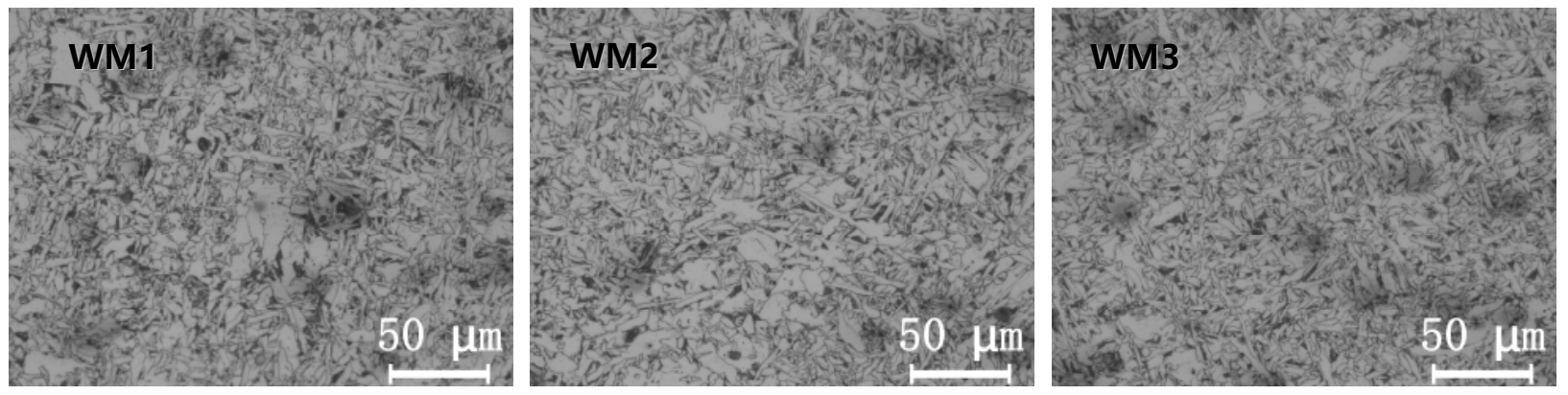

Fig. 5 Optical microstructure of the WM at different position.

Microhardness Distribution. The microstructure and the property of the welding joint has a good corresponding relationship, resulted in the microhardness difference of each microstructure. The results of the microhardness tests were mapped in Fig. 6. It can be found that, the microhardness 
ranges from $190 \sim 220 \mathrm{Hv}$ in the welding zone, while it presents a trough trend of the microhardness in the HAZ ranged from 160 205Hv, and it turns to a wave crest with peak of $225 \mathrm{Hv}$. The obvious soften phenomena occurs at the FZHAZ region with the minimum value of $160 \mathrm{Hv}$. The microhardness distributions along line $\mathrm{a}$ and $\mathrm{b}$ are similar, however, the variation rage of the microhardness in line $b$ is relatively narrow and gentle, resulted by a relatively lower weld heat input at the root. The microhardness distribution also present a mirror symmetry distributed feature in accordance with the distribution of each HAZ region.

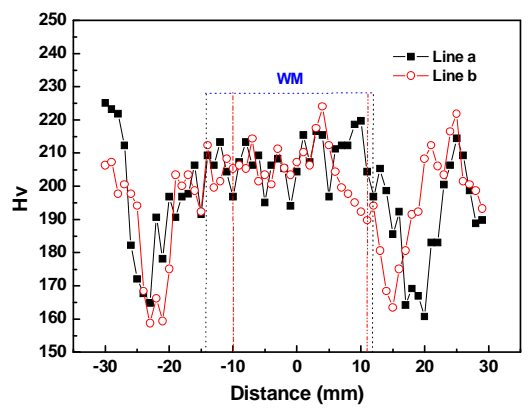

Fig. 6 Microhardness testing distributions of the weld joints.

Electrochemical Behavior. The linear polarization curves of the FCB WMs in a $3.5 \% \mathrm{NaCl}$ solution prepared from different WM regions are shown in Fig. 7. The LP line of WM1 at top WM region presents a slight deviation, while the LP lines of WM2 and WM3 at middle and root WM region show steady and linear. It can be seen that the electrochemical behavior of WM2 and WM3 is similar. By calculated the linear polarization resistances (LPR) from Fig. 7, it decreases gradually from top WM region to root WM region, with the value of $2296.9 \mathrm{Ohm} . \mathrm{cm}^{2}, 1712.5 \mathrm{Ohm} . \mathrm{cm}^{2}$ and 1594.6 Ohm.cm², respectively. According to the corrosion dynamics, the high strength low-alloy steel with higher LPR shows good anti-corrosion property [8]. According to the result of the LP tests, it can be concluded that there is the possibility to generate the galvanic corrosion in the WM due to the different micro-area potential distribution.

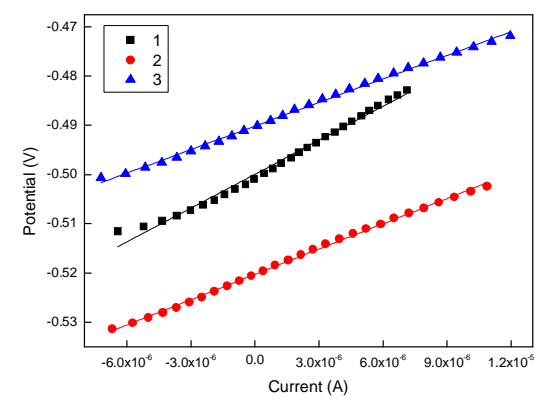

Fig. 7 Linear polarization curves of the FCB WMs.

The EIS responses of different FCB WMs in a 3.5\% $\mathrm{NaCl}$ solution were done at the OCP to further study the difference of the electrochemical behavior, the results are shown as the Nyquist, Bode, and Bode-phase plots in Fig. 8. The Nyquist plots of each sample shows an imperfect semicircle (Fig. 8a), represented as the capacitive arc. The imperfect semicircle diameter of WM1 was largest, which means the top WM region possesses the largest capacitive arc, as reflected the best passivation behavior. Moreover, the imperfect semicircle diameter for the middle WM2 is higher than that of the root WM3. This trend agrees well with the LP results. At the low frequency range of the Bode plots (Fig. 8b), the sample with higher electrical resistance value possess stronger corrosion resistance, the results are consistent with the analysis of the above Nyquist plots. As seen in Fig. 8c, the Bode-phase curves of each WM shows certain constant value at the middle frequency range. And the maximum phase angles values remained between $50^{\circ}$ and $60^{\circ}$, which revealed the formation and growth of the corrosion pits at middle frequency [14], as confirmed the similar 
capacitive response of all WMs. There were not evidences revealed the formation of a passive film because all phase angles values remained far below to $80^{\circ}$, which indicates an impure or non-ideal capacitive response [15]. In other words, the mechanism of pitting corrosion dominates before the formation of oxide film works.
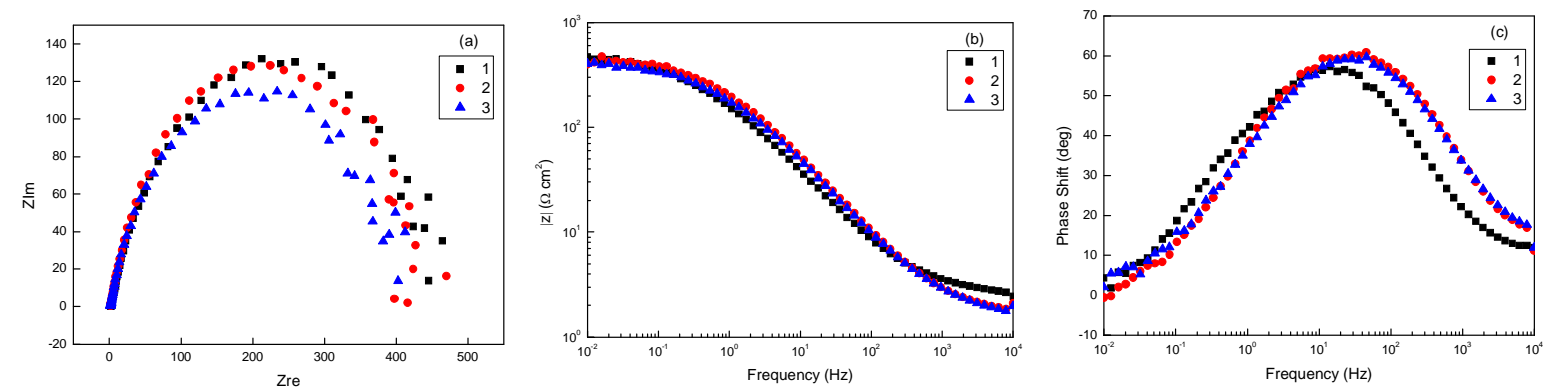

Fig. 8 (a) Nyquist, (b) Bode and (c) Bode-phase plots of each FCB WM at the OCP.

To simulate the measured impedance data, the equivalent circuit shown in Fig. 9 was used [16], and the variations in the impedance parameters are shown in Table 3. In this equivalent model, Rs is the solution resistance; Rpit stands for the resistance of the corrosion pits, and CPE1 counts for the constant phase element corresponding to the capacitance of the corrosion pits; Rct represents the charge transfer resistance of metal to electrolyte, which can be defined as the corrosion resistance of the sample in the electrolyte, and CPE2 counts for the constant phase element corresponding to the metal, which can be recognized as an electrical double-layer capacitor.

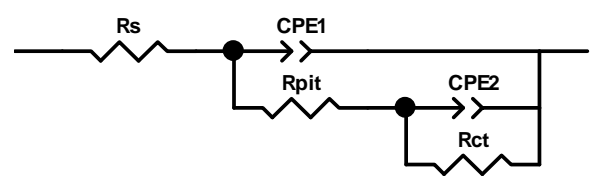

Fig. 9 Best equivalent circuit used to model the experimental EIS data.

The Rct value of each WM region also shows a same downward trend from top to root as the LPR value. The top WM1 has the highest Rct value of $449.9 \Omega \cdot \mathrm{cm}^{2}$, which means that the EH36 base metal possesses stronger anti corrosion ability than the middle WM2 and the root WM3. It may be explained by the different size of the GBF distributed in the WMs (Fig. 7). For the similar FCB WM microstructure benefited by the one-pass welding, the difference of Rct in different WM regions was not obvious.

Table 3. Variations in the impedance parameters of the EIS tested samples.

\begin{tabular}{cccccccc}
\hline $\mathrm{WM}$ & $\mathrm{Rs}\left(\Omega \cdot \mathrm{cm}^{2}\right)$ & CPE1-T(mf) & CPE1-P & Rpit $\left(\Omega \cdot \mathrm{cm}^{2}\right)$ & CPE2-T(mf) & CPE2-P & $\operatorname{Rct}\left(\Omega \cdot \mathrm{cm}^{2}\right)$ \\
\hline 1 & 2.23 & 0.0013 & 0.65 & 4.64 & 0.0001 & 0.89 & 449.9 \\
2 & 1.56 & 0.0003 & 0.51 & 2.08 & 0.0006 & 0.77 & 444.2 \\
3 & 3.14 & 0.0005 & 0.32 & 5.26 & 0.0007 & 0.75 & 443.8 \\
\hline
\end{tabular}

\section{Conclusion}

The EH36 FCB weld joint fabricated at $190 \mathrm{~kJ} / \mathrm{cm}$ weld heat input present mirror symmetrical structure. The HAZ of the EH36 FCB weld joint is consisted of four regions: CGHAZ, transition zone, FGHAZ and ICHAZ. The CGHAZ region is narrow with the thickness variation. A soften phenomenon occurs at the FGHAZ region. The FCB WMs are mainly consisted of acicular ferrite and grain-boundary ferrite, which can been characterized as an integrity with slight regional variation of microstructure and electrochemical behavior. 


\section{Acknowledgement}

This research was supported by the National Natural Science Foundation of China (No. 51601043), the National Project of International S\&T Cooperation Program (2014DFR50310), the Science and Technology Project of Guangdong and Guangzhou (201101C0104901263, 2012A061400011, 2013B050800028/30, 2014B050503004, 2015B050502005, 201508030024).

\section{References}

[1] H. Xie, L. X. Du, J. Hu, R. D. K. Misra, Microstructure and mechanical properties of a novel $1000 \mathrm{MPa}$ grade TMCP low carbon microalloyed steel with combination of high strength and excellent toughness, Mater. Sci. Eng.: A, (612) (2014) 123-130.

[2] C. H. Lee, H. S. Shin, K. T. Park. Evaluation of high strength TMCP steel weld for use in cold regions, J. Constr. Steel Res. (74) (2014) 134-139.

[3] C. F. Fang, X. H. Meng, et al. TANDEM and GMAW Twin Wire Welding of EH36 Steel Used in Hydraulic Support, J. Iron Steel Res. Int. 19(5) (2012) 79-85.

[4] J. Hu, L. X. Du, J. J. Wang, C. R. Gao, Effect of welding heat input on microstructures and toughness in simulated CGHAZ of V-N high strength steel, Mater. Sci. Eng.: A, (577) (2013) $161-168$.

[5] M. C. Zhao, K. Yang, Y. Shan, The effects of thermo-mechanical control process on microstructures and mechanical properties of a commercial pipeline, Mater. Sci. Eng.: A, (335) (2002) 14-20.

[6] J. Moon, S. J. Kim, C. Lee, Effect of thermo-mechanical cycling on the microstructure and strength of lath martensite in the weld CGHAZ of HSLA steel, Mater. Sci. Eng.: A, (528) (2011) $7658-7662$.

[7] J. Hu, L. Du, H. Xie, F. Dong, R. D. K. Misra, Effect of weld peak temperature on the microstructure, hardness, and transformation kinetics of simulated heat affected zone of hot rolled ultra-low carbon high strength Ti-Mo ferritic steel, Mater. Des. (60) (2014) 302-309.

[8] H. Ma, Z. Liu, C. Du, X. Li, Z. Cui. Comparative study of the SCC behaviour of E690 steel and simulated HAZ microstructures in a $\mathrm{SO}_{2}$-polluted marine atmosphere, Mater. Sci. Eng.: A, (650) (2016) 93-101.

[9] L. Lan, C. Qiu, H. Song, D. Zhao, Correlation of martensite-austenite constituent and cleavage crack initiation in welding heat affected zone of low carbon bainitic steel, Mater. Lett. (125) (2014) 86-88.

[10]W. Guo, D. Crowther, J. A. Francis, A. Thompson, Z. Liu, L. Li, Microstructure and mechanical properties of laser welded S960 high strength steel, Mater. Des. (85) (2015) 534-548.

[11] S. H. Wang, C. C. Chiang, S. L. I. Chan, Effect of initial microstructure on the creep behavior of TMCP EH36 and SM490C steels, Mater. Sci. Eng.: A (344) (2003) 288-295.

[12] S. Qu, Y. Zhang, X. Pang, K. Gao, Influence of temperature field on the microstructure of low carbon microalloyed ferrite-bainite dual-phase steel during heat treatment, Mater. Sci. Eng.: A, (536) (2012) 136-142.

[13] S. Jindal, R. Chhibber, N. P. Mehta, Issues in welding of HSLA steels, Adv. Mater. Des. (365) (2012) 44-49.

[14] J. Soltis, K. A. Lichti, Galvanic corrosion of carbon steel coupled to antimony, Corr. Sci. (68) (2013) 162-167. 
[15]H. Y. Ha, M. H. Janga, T. H. Lee, J. Moon, Interpretation of the relation between ferrite fraction and pitting corrosion resistance of commercial 2205 duplex stainless steel, Corr. Sci. (89) (2014) 154-162.

[16]S. Qu, X. Pang, Y. Wang, K. Gao, Corrosion behavior of each phase in low carbon micro alloyed ferrite-bainite dual-phase steel: Experiments and modeling, Corr. Sci. (75) (2013) 67-77. 